\title{
Assessment of Coffee Berry Disease in West Hararge Zone, Eastern Ethiopia
}

\author{
Abdi Adem ${ }^{1, *}$, Mohammedsani Amin', Mulugeta Mamo \\ ${ }^{1}$ Department of Horticulture, Dilla University, P.O.Box 419, Dilla, Ethiopia. \\ ${ }^{2}$ Mechara Agricultural Research Centre, West Hararge, P.O.Box 19, Mechara, Ethiopia.
}

How to cite this paper: Abdi Adem, Mohammedsani Amin, Mulugeta Mamo. (2020) Assessment of Coffee Berry Disease in West Hararge Zone, Eastern Ethiopia. International Journal of the Science of Food and Agriculture, 4(4), 465-469. DOI: 10.26855/ijfsa.2020.12.015

Received: November 6, 2020

Accepted: November 30, 2020

Published: December 18, 2020

*Corresponding author: Abdi Adem, Department of Horticulture, Dilla University, P.O.Box 419, Dilla, Ethiopia. Email: abdi.ademame@gmail.com

\begin{abstract}
Coffee is principal cash crop in Ethiopia. Harar coffee is one of the coffee types of Ethiopia known for their fine quality unique aroma and flavor. Large proportion of Harar coffee is produced in West Hararge Zone in Eastern Ethiopia. Coffee berry disease causes yield loss of $25 \%-30 \%$ at national level. It also deteriorates cup quality of coffee. There was a need to study status of coffee berry disease in West Hararge Zone. Accordingly, this study was conducted with the objective to determine incidence and severity of coffee berry disease in West Hararge Zone. Total of 135 coffee farms at 27 study sites in three districts (DaroLabu, Habro and Boke) were used for this study. The study farms were selected using multi stage sampling techniques. Incidence of CBD was determined as percentage of diseased trees by visual assessment on 10-15 trees/farm. CBD severity was determined as percentage of diseased coffee berries. Data were analyzed for descriptive statistics (mean, range, percentage). The result of this study revealed that incidence of CBD varied among study sites. CBD incidence in West Hararge varied from $8.0 \%$ to $84.0 \%$ with mean of $49.7 \%$. On the other hand, severity of coffee berry disease ranged from $0.0 \%$ to $26.7 \%$ with mean of $10.0 \%$. Both incidence and severity of the disease varied across study districts and sites. Hot spot areas were identified. Hence, it is advisable to introduce CBD resistant coffee varieties for production in hot spot areas. Training farmers to use cultural control methods such as pruning, sucker management is also the way forward.
\end{abstract}

\section{Keywords}

Coffee berry disease, Eastern Ethiopia, Incidence, Severity

\section{Introduction}

Coffee is the principal cash crop in Ethiopia. The country is the $5^{\text {th }}$ and $1^{\text {st }}$ coffee producer in the world and in Africa, respectively [1]. Coffee is a means of livelihood for about one-fourth of the country's population. In 207/18, Ethiopia earned 839 million dollar from coffee export, accounting for about 30\% of income from all commodities [2]. Ethiopia is the center of origin and diversity for Arabica coffee [3]. The coffee types of Ethiopia that are distinguished for their very fine quality, unique aroma and flavor characteristics include Harar, Sidamo, Yirgacheffe, Ghimbi and Limu types [4].

Harar coffee accounted for $10 \%$ of the total country's coffee acreage and $8 \%$ of the country's coffee export [5]. It is grown in Eastern Ethiopia in altitude ranging from 1,510 to 2,120 masl. West Hararge Zone is the major producer of Harar coffee. In the area, coffee is produced in highly diversified garden production systems adapted to different ecological conditions. In the area, coffee is intercropped with the mild stimulant perennial crop "chat" (Chataedulis), sorghum, maize, beans and sweet potato. Farmers of the area grow coffee landraces having their own characteristic features 
[6]. Harerge coffee fetches premium prices in the world market. But this resource is under threat of erosion mainly because of chat (cathaedulis) expansion [3].

In 2017, area devoted to coffee production in west Hararge Zone was 7,746 ha with yield of 0.6 ton/ha [7]. The low yield of coffee in the Zones stems from several factors including diseases. Harar coffee is susceptible to coffee berry disease. Coffee berry disease is the major disease of coffee in the country. CBD causes yield loss of $25 \%-30 \%$ at national level. The disease affects flower, fruits and branches of the coffee plant. It causes premature fruit drop and mummified fruits and thereby reduce both yield and cup quality of coffee [8, 9]. Hence, there was a need to study status of coffee berry disease is Harar coffee grower areas. Accordingly, this study was conducted with the objective to determine incidence and severity of coffee berry disease (CBD) in West Hararge Zone.

\section{Methods}

\subsection{Study Sites and Sampling}

This study was conducted in August 2014 in West Hararge Zone. The study area is bordered on the south by Bale Zone, on the east by East Hararge, the northeast by Somale region. Three districts namely Darolabu, Habro and Boke (Figure 1) were purposively selected for their coffee production potential. Altitude of study sites varied from 1,658 to 1,833 masl in Darolabu district, 1,721 to 1,772 masl in Habro and 1,762 to 1,855 masl in Boke district. From each district, nine representative study sites were selected through discussion with districts' coffee experts and mainly based on coffee production potential and representativeness. Then, five coffee farms (at distance of 3-5 Km) were selected for study. Hence total of 135 coffee farms were used for the study.

\subsection{Data Collection and Analysis}

Incidence and severity of coffee berry disease were recorded as follows.

Incidence of coffee berry disease (CBD): Incidence of CBD was recorded on 10-15 coffee trees/farm by visual assessment. Sample coffee trees were randomly selected. Then the selected coffee trees were diagnosed for presence and absence of the disease. The disease incidence was calculated as percentage of diseased trees.

Severity of coffee berry disease: CBD severity was determined using berry counting method. About 10-15 coffee trees/farm were randomly selected, following diagonal and zigzag method. Each tree was divided into three strata of branches (top, middle and bottom). From each stratum one branch was selected. Then, CBD infected as well as healthy berries were counted. Finally, CBD incidence (\%) was determined as percentage of diseased coffee berries. Descriptive statistics such as mean, percentage, range were analyzed. The results were presented in the form of charts the northeast by Somale region.

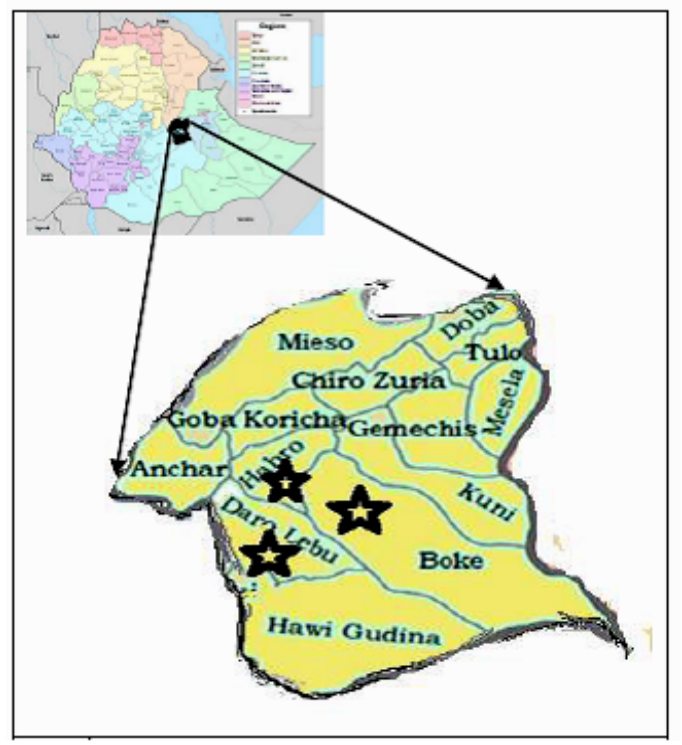

Figure 1. Map of West Hararge Zone and study districts (star).

\section{Results and Discussion}

\subsection{Incidence of coffee berry disease (CBD)}

The result of this study revealed that incidence of CBD varied across study sites. CBD incidence varied from 8.0\% at Bukeguddo of Boke district to $84.0 \%$ at Firi Jiru kebele of Habro district with mean of 49.7\%. In this study, CBD inci- 
dence ranged from 8.0 to $60.0 \%$ with mean of $37.2 \%$ at Darolabu district, $32.0 \%$ to $84.0 \%$ with mean of $59.3 \%$ at Habro district and $8.0 \%$ to $75.0 \%$ with mean values of $52.5 \%$ at Boke district. In Darolabu district, CBD incidence varied from $8.0 \%$ to $64.0 \%$ with mean of $37.2 \%$ (Figure 2). The highest CBD incidence (60.0\%) was recorded at Odda Anesso followed by Tutis (48.0\%), Mechara (46.7\%), Sororo and Sakina (40\%). In Habro district, the minimum and maximum incidence of CBD were $32.0 \%$ and $84.0 \%$ while the mean value was $59.3 \%$ (Figure 3 ). The highest CBD incidence (84.0\%) was recorded at Firi Jiru followed by Defo (80.0\%), Ifa jiru matamura (75\%), Dikicha Dhabaa (66.7\%), Odaa Annanii (65.0\%) and Dikicha Babbo (50\%). On the other hand, CBD incidence was 8.0\% to 75\% with mean of 52.5\% in Boke district (Figure 4). Areas with high CBD incidence, in the district, were Iddo aroji-2 (75\%), Haromuda (66.7\%), Soraa (65.0\%), Cabbi (63.3\%), Iddo Arojjii-3 and Iddo Arojjii-1 (60\%). The result of this study is comparable with study conducted in different parts of the country. For instance, Arega [10] reported that CBD incidence varied from 0\%-50\% in Bale area, 20\%-60\% in Bonga, $0 \%-20 \%$ in Sheko and $0 \%-50 \%$ in Yayu areas. The result of study conducted in 1994 depicted that mean incidence of CBD was 38.8\% and 17\% in Oromia and Southern Regional States, respectively $[11,13]$. The minor discrepancies with our study may be due differences in study areas and time of study. The incidence and severity of CBD was very high in especially at higher altitudes and in valley bottoms. Similar findings were reported by [12] who studied status of CBD in different parts of southern region of the country.

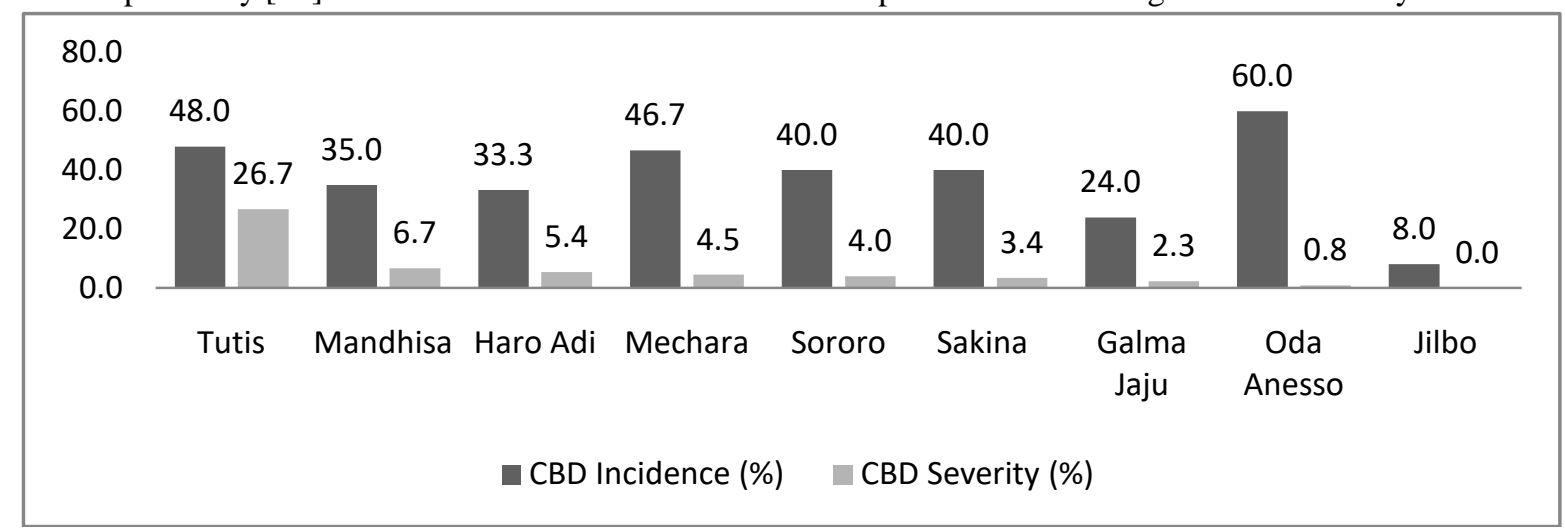

Figure 2. Status of Coffee berry disease in Daro labu district, 2014.

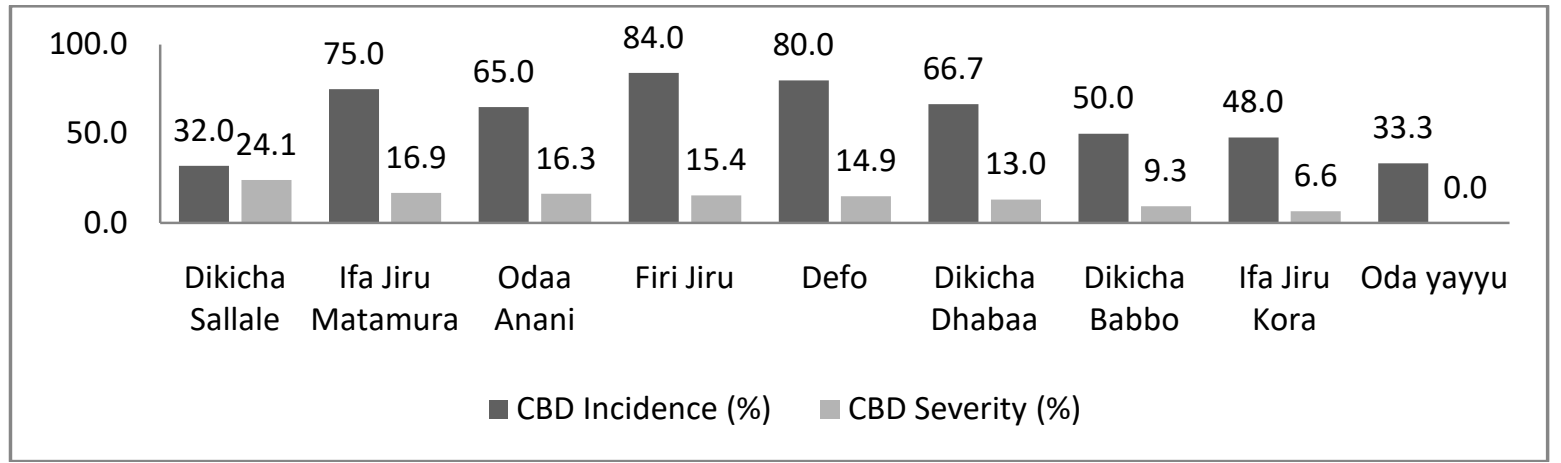

Figure 3. Status of Coffee berry disease in Habro district, 2014.

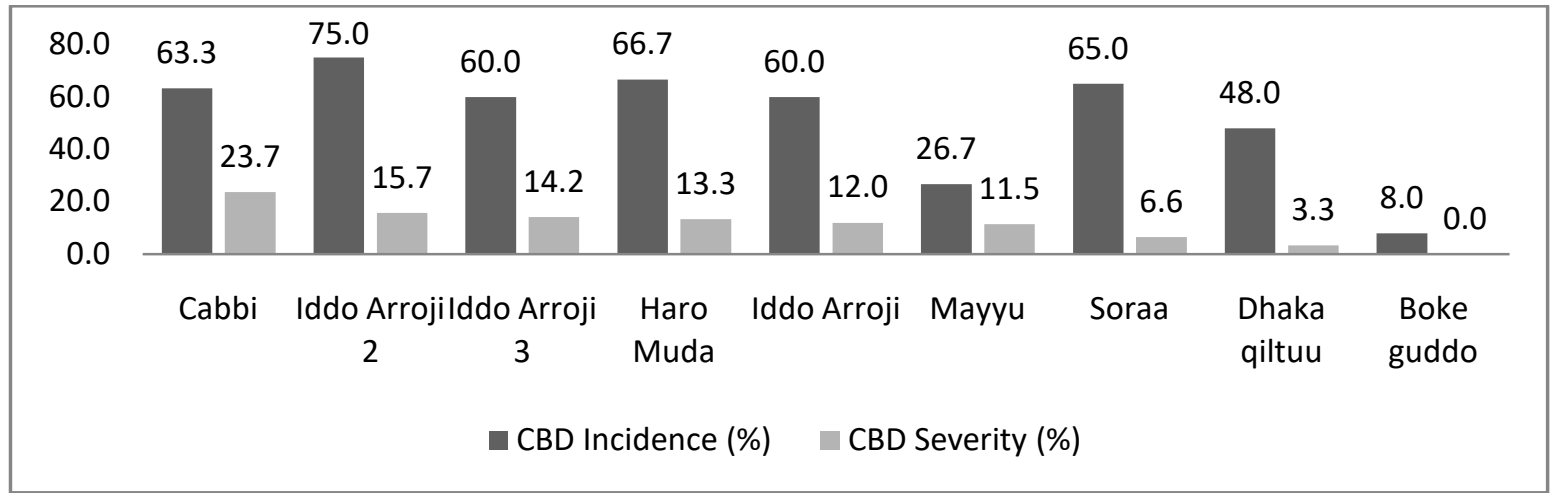

Figure 4. Status of Coffee berry disease in Boke district, 2014. 


\subsection{Severity of coffee berry disease (CBD)}

Severity of coffee berry disease throughout 27 study sites ranged from 0.0 at Jilbo (in Darolabu district) and Bokeguddo (in Boke district) to $26.7 \%$ at Tutis Kebele of Darolabu district with mean of $10.0 \%$. CBD severity varied across studied districts and sites. In Darolabu district, CBD severity varied from $0.0 \%$ at Jilbo to $26.7 \%$ at Tutis with mean value of 6.0\% (Figure 2). Highest CBD incidence was recorded at Tutis (26.7\%) followed by Mandhisa (6.7\%), HaroAdi (5.4\%), Mechara (4.5\%) and Sororo (4.0\%). In Habro district, the lowest CBD severity (0.0\%) and the highest severity $(24.1 \%$ were recorded at Odayaayyu and Dikichasalale, respectively (Figure 3). Mean severity of the disease was $12.9 \%$. Disease severity varied across study sites in the district. The CBD severity of $24.1 \%, 16.9 \%, 16.3 \%, 15.4 \%$ and 14.9\% were recorded at Dikicha Sallale, Ifajiru matatuma, Oda Anani, Firi Jiru and Defo in that order. In Boke districts, CBD severity varied from 0.0 at Bokeguddo to $23.7 \%$ at Cabbi with mean of $11.1 \%$ (Figure 4).

The result of our study further revealed that CBD severity was less than incidence at all study sites. Incidence occurred in all the 27 study sites. This shows that CBD is important disease in West Hararge. Hot spot areas were identified from the present study. In DaroLabu district, Tutis, Mandhisa and HaroAdi were hot spot areas for CBD. DikichaSalale, IfaJiruMatamura, OdaAnani, Firi Jiru, Defo and DikichaDhaba are hot spot areas in Habro district. It is important to note that CBD severity was high in Habro and Boke districts than in Darolabu district. The weather of Darolabu district is drier than that of Habro and Boke districts. On the other hand, Cabbi, Iddo Arrojji-2, Iddo Arrojjii-3, HaroMuda, Iddo Arrojji-1 and Mayyu were hot spot areas in Boke district. The result of studies conducted in other parts of the country revealed CBD severity varied from 0.9 to $15 \%$ in Bale, $12.5 \%$ to $22.5 \%$ in Bonga, $0.0 \%$ to $6.5 \%$ in Sheko and $0.0 \%$ to $7.8 \%$ in Yayu [10]. The result of survey conducted in six major coffee growing zones of Oromia regional state in 1997 and 1998 revealed average CBD severity was of 31.5\%. That study further showed that CBD severity was 42.0\% in West Hararge Zone [13]. The mean CBD severity recorded in our study (10.0\%) is lower than CBD severity (42.0\%) reported in West Hararge in late 1997/98. The variation from our study may be due to difference in study sites and the rise of temperature over the last 14 years due to climate change. CBD is favored by low temperature and high relative humidity. CBD can cause yield loss of up 100\% [14] when host plant is susceptible, environment is suitable for the disease to occur and the pathogen is virulent.

\section{Conclusion}

The result of our study revealed CBD occurred across all study districts and sites. CBD incidence in West Hararge varied from $8.0 \%$ to $84.0 \%$ with mean of $49.7 \%$. On the other hand severity of the disease ranged from $0.0 \%$ to $26.7 \%$ with mean of $10.0 \%$. Both incidence and severity of the disease varied across study districts and sites. CBD incidence ranged from $8.0 \%$ to $60.0 \%$ with mean of $37.2 \%$ at Darolabu district, 32.0 to $84.0 \%$ with mean of $59.3 \%$ at Habro district and 8.0 to $75.0 \%$ with mean values of $52.5 \%$ at Boke district. On the other hand, CBD severity varied from $0.0 \%$ to 26.7\%, 0.0 to $24.1 \%$ and 0.0 to $23.7 \%$ in Darolabu, Habro and Boke districts, respectively. The mean severity of CBD was $6.0 \%$ in Darolabu, $12.9 \%$ in Habro and $11.1 \%$ in Boke districts Disease severity was moderate to high in most of study sites in Habro and Boke districts. Hence, it is advisable to introduce CBD resistant coffee varieties for production in hot spot areas. Training farmers to implement cultural control methods such as plant pruning, sucker management is also the way forward.

\section{References}

[1] FAO. (2020). Food and Agricultural Organization, FAO data base by crop, area, yield and production. Food andAgriculturalOrganization. Available on: http://faostat.fao.org/site/567/DesktopDefault.aspx ?Page ID= 567\#ancor.

[2] NBE. (2019). National Bank of Ethiopia Annual Report of the year 2017/18, pp. 67-69.

[3] Bayeta, B., Labouisse, J. P., Hamelin, C., Kotecha, S., and Bertrand, B. (2007). Collection and ex-situ conservation of coffee landraces in Ethiopia: The example of Harerge In: $21^{\text {st }}$ International Conference on Coffee Science, Montpellier (France), $11^{\text {th }}$ to $15^{\text {th }}$ September 2006.ASIC, pp. 926-930.

[4] Workafes, W. and Kassu, K. (2000). Coffee production system in Ethiopia, In: Proceedings of the Workshop on Control of Coffee Berry Disease in Ethiopia. 13-15 ${ }^{\text {th }}$ August, 1999, Addis Ababa, Ethiopia.

[5] Desse, N. (2008). Mapping Quality profiles of Ethiopian Coffee by Origin. In: Proceeding of a National Workshop Four Decades of Coffee Research and Development in Ethiopia, 14-17 August 2007, Addis Ababa, Ethiopia. Pp. 317-327.

[6] Bayeta Bellachew, Bahilu Atero, and FikaduTefera. (2000). Breeding for resistance to Coffee Berry Disease in arabica coffee: Progress since 1973. Proceedings of the workshop on control of Coffee Berry Disease in Ethiopia, Addis Ababa (Ghion Hotel), August 13-15, 1999, Addis Ababa, Ethiopia.

[7] CSA. (2017). Central Statistical Agency of Ethiopia. Report on Area and Production of major crops in Ethiopia. Annual Agricultural Sample Survey of 2016/17 Statistical Bulletin 584. Volume I. Addis Ababa, Ethiopia, pp. 50-53. 
[8] Tefesetewold, B. (1995). Studies of Colletotrichumpopulation on Coffeaarabica L. In Ethiopia and evaluations of the reactions of coffee germplasm. PhD Dissertation, University of Bonn, Germany. Pp. 231.

[9] Eshetu, D., et al. (2000). Control of coffee berry disease by fungicides in Ethiopia. In: Proceedings of the workshop on control of coffee berrydisease (CBD) in Ethiopia. August 13-15, 1999, Addis Ababa, Ethiopia. Pp. 35-46.

[10] Arega, Z. (2006). Diversity of arabica coffee populations in afromontane rainforests of Ethiopia in relation to Colletotrichumkahawae and Gibberellaxylarioides. M.Sc. Thesis, Addis Ababa University, Ethiopia. P. 81.

[11] Tesfaye Negash and Sinedu Abate. (2000). Status of CBD in SNNP. In: Proceedings of the Workshop on Control of Coffee Berry Disease (CBD) in Ethiopia, pp. 18-28. August 13-15, 1999, Addis Ababa, Ethiopia.

[12] Merdassa, E. (1986). A review of coffee diseases and their control in Ethiopia. In: Proceedings of the First Ethiopian Crop Protection Symposium. February 4-7, 1986. IAR, Addis Ababa, Ethiopia. (Tsedeke Abate, ed.). Pp. 187-195.

[13] Melaku, J. and Samuel, A. (2000). Status of coffee berry disease in Oromia. In: Proceedings of the Workshop on Control of Coffee Berry Disease (CBD) in Ethiopia. August 13-15, 1999, Addis Ababa, Ethiopia. Pp. 18-28.

[14] Van der Graff, N. A. (1981). Selection for Arabica coffee types resistant to CBD in Ethiopia, Mededelingen Lonbovwhogeschola,Wageningen, p. 110. 